\title{
LA VIDA MUNICIPAL DEL MADRID FILIPINO
}

\section{Interesantes referencias del Ayuntamiento, de 1722 , recogidas por su secretario Martín M. Vargas}

Adviértese de algún tiempo a esta parte creciente afán por los estudios referentes al Madrid pretćrito. Exhúmanse y analízanse documentos de los archivos, se divulga su contenido, con el propósito de inferir de las añejas noticias las trayectorias seguidas por la villa del Manzanares antes y después de su exaltación a la cabecera nacional. Congratulémonos del hecho no sólo porque: "descubre" el pasado de Madrid, sino porque el conocimiento de Madrid da la clave muchas veces de la historia patria en las íltimas centurias.

No perdamos de vista las funciones directivas y aglutinadoras que juegan las capitales de los Estados, y que Madrid es el crisol de la raza y el más fiel exponente del pueblo español.

Existe un documento muy valioso del Madrid filipino, que hasta el presente apenas es conocido. Se trata de las "referencias" del funcionamiento municipal de Madrid en I722, "rerogidas por el secretario del Concejo de aquel entonces, Martín Marcelino Vargas; según nuestras noticias, no hay más ejemplar del documento que el redactado por el propio secretario. Hace años que debería estar impreso, pues a través de sus informes se refleja la vida local y se puede formar juicio acabado de la organización y actuación de la Municipalidad. Por cierto que el cuadro que Madrid of rece no coincide exactamente con las versiones de los historiadores de esas épocas.

El trabajo de Vargas corrobora la tesis mantenida por el Congreso Históricomunicipalista de Palma de Mallorca de 1926, 04 en el que se proclamó que la historia verdadera de España no 
podrá forjarse hasta que se bucee con cuidado en los fondos de los archivos de los pueblos, se cataloguen y se interpreten con criterio cientifico.

\section{Organización del Concejo madrileño en 1722}

Integraban el Concejo de Madrid en la fecha indicada 41 caballeros regidores, presididos por el corregidor, todos nombrados por la Realeza. Ya habian sido aniquiladas las libertades comunales, a consecuencia de la rota de Villalar. Impera el régimen absolutista: el Estado es el Rey, según la estereotipada frase que se atribuye a Luis XIV.

I.as funciones municipales se agrupaban en 89 comisiones $y$ patronatos. "Es costumbre inconcusa-escribe Vargas-de $\mathrm{Ma}$ drid sortear entre los $4 \mathrm{I}$ caballeros regidores, con el nombre de comisiones, aquellas dependencias que tienen alguna utilidar, estimación o regalía."

Ias comisiones principales erar las de Alcabalas, Cientos; Millones, Tasa y Retasa de Casas, Sisa, Autos y Fiestas del Corpus, Abastos, Sexmos, Vecinos y Soldados. La mayoría constaban de dos regidores, uno antiguo y otro moderno. Las demás comisiones y los patronatos tenian a su frente un regidor, antignto o moderno, sin distinción. El sorteo se verificaba en la sála capitular a presencia de la edilidad, debiéndose avisar a todos los que se hallaban en la villa, sanos o impedidos. Tal obligación no rezaba con los ausentes.

Desde 1756 se prohibian las reelecciones. Los regidores no podian volver a la misma comisión o patronato hasta que los otros hubieran desfilado por ella. Las elecciones se hacían cada año el dia $1 .^{\circ}$ de enero.

\section{Comisión de Alcabalas de 1342}

Le corresponde asistir a las juntas de repartimiento de los gremis que determinan el encabezamiento con que cada uno ha de contribuir.

Debe cobrarse el 10 por 100 de todo ló que se vende, permuta e impone.

Por las tercias reales, dos novenas de todos los diezmos.

Madrid nombra tesorero para la percepción y cobro, teniendo que recaer el que será propuesto por los diputados en quienes 
tengan abierta tienda en la Puerta de Guadalajara, calle Mayor, de Postas o Portal de los Paños. Ha de ser afianzada la Tesoreria por cuatro gremios.

\section{Comisión de millones de 1530}

Data de 1530, de Felipe II, por la concesión que se hizo al Rey de ocho millones para la "Invencible".

Con diversos motivos se establecieron otros tributos luego. - Pagan las sisas todos, excepto los eclesiásticos. Los impuestos son los siguientes:

Maraveúises

Libra de carnero, cava o tocino, al por menor .......

Cabeza de cordero o tocino, al por mayor ............

Arreba de vino .................................... $6_{4}$

Arroba de aceite ................................. I

I ibra de jabón y velas de sebo ..................... 4

Arroba de vinagre ................................ $\quad$ I6

Esto es para el caso de Madrid.

3

102

Es deber de los miembros de la comisión asistir a las juntas de los hacimientos de rentas, que se celebran en las Casas del Ayuntamiento a fin de año con los demás caballeros comisarios.

J)espués de las Cortes de 1643 y 1655 se concedieron los servicios de

24 millones.

8.000 soldados.

2,5 millones.

9 millones de plata.

I millón de quiebras.

Impuesto de pesas, etc.

Estos servicios han ido siendo prorrogados por tiempo limitado, generalmente por períodos de seis años, para lo que el Rey lo pide a las' ciudades y villas con voto en Cortes.

En I6r3 Madrid se avino al servicio de 18 millones, cargado sobre vino, vinagre, aceite y carne, bajo ciertas condiciones.

Al trasladarse de nuevo la Corte a Madrid se concedió e! privilegio de que mediante el abono de 250.000 ducados se le eximie66 ra del tributo de la sexta parte de los alquileres y, consiguientemen- 
te, de las vejaciones a él inherentes. No fué respetada la concesión, fues aunque Madrid abonó los 250.000 ducados en el plazo convenido, siguieron percibiendo los tributos sobre los alquileres.

\section{Comisión de tasas y retasas de casas, de 1619}

Tiene su origen en 1613 , por virtud del servicio de $250.000 \mathrm{du}$ cados que hizo Madrid al Rey, por vía de transacción de la sexta parte de los alquileres concertada al volver la Corte a Madrid.

For cédula de 16 i 3 se mandó que los alcaldes de Corte, uno cacle día y por orden de angüiedad, asistiesen a las tasas de las casas con $\epsilon$ l caballero regidor y el aposentador que le tocase, y que de. lo que se percibiera deducieran previamente la sisa, se entregaran 40.000 maravedises a cada uno de los seis alcaldes, seis regidores y seis aposentadores.

En 1663, en vista de lo elevado de las retribuciones, se dispuso que desempeñaran el cometido un solo alcalde, un regidor y un aposentador, el más antiguo, percibiendo los 40.000 maravedises, y que si hubiera que hacer retasas por agravio de las partes, se nombrará el presidente, pero sin aumentar los dispendios. Pero recurrieron los alcaldes, y en i668 el Rey les atendió. Para los regidores. y aposentadores perseveró la orden.

Por lo que respecta a las retasas, la comisión se estableció en 1715 .

\section{Comisión de cientos de 1639}

Los miembros de la comisión han de concurrir a las juntas de ventas y repartimientos de alcabalas y nombramientos de diputados de rentas.

Se creó, al conceder en 1639 el primer I por 100-que en I5́ 2 se elevó otro I-, para servir al Rey en parte del payo de los nueve millones de plata concedidos en dichos años.

Concedióse otro I por 100 en 1856 , y otro - el cuarto en 1665 .

\section{Comisión de autos y fiestas del "Corpus", de 1317}

Fórmanla cuatro caballeros regidores: dos antiguos y dos modernos.

Tiene a su cargo cuidar de todo lo preciso del día del Corpus: 67 
danzas, jarasca, gigantes, toros, adorno de la iglesia y calles por donde ha de pasar la procesión.

Forma las compañías para la representación de los autos sacramentales.

I.os caballeros perciben roo ducados cada uno.

Presipuesto de las fiestas:

Reales

Cera

1.700

Música de capilla

2.200

I.as cuatro danzas

2.200

Vestidos para los niños de la Doctrina

3.300

Emprechados y atarfes de las calles

2.500

Fiesta de San Dámaso 768

I.a Tarasca

Vestidos de las danzas y sus herhuras

I. 400

Colgado de toldos

3.300

Composición de gigantes

6.000

600

Alquiler de tapices para bocacalles

I.000

Paños para limpiar la custodia 460

Música 1.000

Sacristanes, maestros de ceremonias, etc., y conducción de ornamentos 426

Capitulares comisarios 2.400

Alguacil mayor 400

Ministros que asisten a la comisión 480

Porteros del corregidor 350

Criatos del protector, corregidor y capitulares 480 Datos que puedan of recer

6.000

En las procesiones del Corpus, que eran en I 723 las más solemnes, el orden de las mismas era el siguiente: Atabales, trompetas, niños desamparados, los de la Doctrina, pendones, cruces, ancianis del Hospital General, los de Antón Martin, Mercenarios Descalzos, Capuchinos, Franciscanos Descalzos, Agustinos Descalzos, Carmelitas Descalzos, Clérigos menores, Padres de la Compañia de Jesús, Mínimos de la Victoria, Jerónimos, Mercenarios Calzados, Trinitarios, Carmelitas, Agustinos, Franciscanos, Dominicos, Basilios, Premostatenses, Bernardos, Benitos, la Cruz 68 de Santa María de la Cabeza, la del Hospital General de la Cor- 
te, la clerecia, en medio de las Ordenes Militares-Alcántara, Calatrava y Santiago, con manto capitular-. A la derecha: el Cọnsejo de la India, el de Aragón, el de Portugal, el Supremo de Castilla. A la izquierda: el de Hacienda, el de Ordenes, el Supremo de la Inquisición, el de Italia. A continuación: el Cabillo de la Clerecia, 24 sacerdotes revestidos con inciensos, la Capilla Real con su guión; tres caperos, el de en medio llevaba el báculo; los paies del rey con hachas, las andas del Santísimo Sacramento, le. Villa con el palio, el Rey, el Infante don Carlos a la izquierda, e! Cardenal Zapata a la derecha, un poco detrás; el Cardenal Spinola al otro lado, el Nuricio en medio de los dos, el Obispo de Pamplona detrás, el Inquisidor general, el embajador de Polonia. el Patriarca de las Indias, el embajador de Francia, el de Venecia, el de Inglaterra, el de Alemania, los grandes cerca de la persona del Rey. los títulos y señores, las tropas en medio de la procesión; las dos guardias, española y tudesca, a los lados de la proresión. y detrás de ella los arcabuceros.

En las referencias que extractamos se citan los personajes aristocráticos que acudieron a la procesión en los años precedentes.

\section{Comisión de sillas municipales de $\mathbf{1 3 4 2}$}

Entendía de la provisión de fondos para proveer a los servicins de Madrid a S. M., buscando personas que prestaran dinero, bien con garantía de las rentas reales, bien con la de las sisas municipales.

Sc ocupaban del arrendamiento de sisas, formando junta con el corregidor y dando cuenta a Madrid en sú Ayuntamiento del resultado del concurso, siendo lo más frecuente que el Avuntamiento devuelva el expediente a la Junta, la que proponga su tramitación hasta que cumplidos los demás trámites se procede a la adjuclicación.

La sisas reales son las que se imponen por concesión del Reino para desempeñar las diferentes urgencias de la Monarquia: son iguales para todas las ciudades, villas y lugares del reino.

Las sisas muniripales son las que, autorizadas por el Rey, se imponen para los servicios particulares que le hizo la ciudad, villa o lugar para pagar censos que no pueda abonar con el producto de sus bienes de propios o para cualquier otra cosa de beneficio común o particular del vecindario. 
Diferénciase la sisa de! tributo en que la sisa se impone en Ios abastos, contribuyendo todos, excepto los eclesiásticos, que sólo contribuyen en los de beneficio común del pueblo.

Fi tributo es un repartimiento o carga concejil que recae sólo en los vasallos.

Las sisas que hay en Madrid son muchas, especialmente sobre los vinos y las carnes. Las del vino, por arroba, son:

\section{Maravedises}

Por las sisas de quiebras de millones .............. 63

$" \quad "$ de los tres millones .................... 3.3

$" \quad "$ del vino de Olivenza ................ I.3

" " del vino bajado de medidas .......... 44

$" \quad "$ del vino de 8.000 soldados $\ldots . . . \ldots . . .4$

$" \quad "$ del vino de la salud .................... 16

$" \quad "$ del vino de la cárcel .................. 7

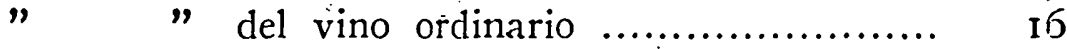

$" \quad "$ del vino de los nuevos impuestos ...... 23

$" \quad "$. del vino de Lérida .................... I4

$" \quad "$ del vino de la plaza ................... 14

$"$ " del vino de la sexta parte ............. I . I

$" \quad$ " del vino por error de medida ........ 4.4

Total

Por cada libra de carne, vendida en la plaza:

Por la sisa de 24 millones $\ldots . . \ldots \ldots \ldots \ldots \ldots \ldots \ldots \ldots . . . \ldots \ldots$

$" \quad$ " moderada de carnes ................... 2

$" \quad$ "nueva de carnes ........................ 2

" $"$ de 8.000 soldados ...................... I

$" \quad "$ del cuarto de Palacio ................... I

$" \quad "$ de quiebras ........................... 2

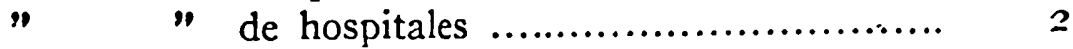

$" \quad "$ de alcabala y cuentos ................. 2

" " de los hospitales por vía de Alcalá ... I 
Por el rastrón de cada carneró, 15 reales.

Origen de las sisas reales y municipales. De las de carnes:

I.a de "24 millones", en 1667 , por diferentes servicios que se hicieron el expresado año.

$\mathrm{La}$ "moderada", en 1656 , por el anticipo de millón y medio de reales que se hizo al rey.

La de "8.000 soldados", en 1653 .

La del "cuarto de Palacio", en I618, por la fábrica de un cuarto que se laboró en Palacio con el nombre de Alcázar cuando vino la Corte a Madrid.

La de "quiebra de millones", en 1656 , por los que se debía de atrasos por las concesiones del reino en los servicios que se hizo al rey.

La de "Hospitales", en I648, por auxilios a los hospitales, subvención a los gastos de la jornada regia en Aragón, y 138.000 ducađos para los gastos del ejército de Cataluña.

t.as del "rastro de fuentes" para pagar los gástos de conducción de aguas a las fuentes públicas y particulares.

Ia "ordinaria" es de las primitivas de Madrid y se aplicó al pago de los censos anteriores a i6i 7 .

(Irígenes de las sisas del vino:

La "ordinaria" es muy antigua y se impuso para abonar compras de trigo y para obras y ornato de Policía, prorrogándose en I 533 para el pago de diferentes servicios que se hicieron:

I a de la "sexta parte" procede del servicio que se hizo en I6r7 al rey de 250.000 ducados con la sexta parte de los alquileres de diez años.

- La del vino de la plaza, Le r6r\&, para el pago de las casas que se derruyeron para hacer la Plaza Mayor.

I.a del "vino de I.érida", de I644, para los gastos de la guerra de Cataluña, sitio y defensa de la plaza de Lérida.

La de "cárcel", de 1630, por las obras de la cárcel de Corte.

La de la "salud", de 1637 , por los gastos de la guarda cle la" peste que hubo en Málaga.

Ia de "8.000 soldados", de 1654, para el pago de diversos ser-" vicios.

La de "vino de Olivenza" para el pago de de 200.000 ducados para el socorro del sitio de Olivenza.

La de "tres millones", de 1657, para el abono de 300.000 escudos al rey. 
La de "bajada de medidas", de I663, para el pago de 500.000 escudos de a ro reales vellón, quedando reducida la arroba menos a 12 azumbres.

Ia de "quiebras de millones", de 16.37 , que se impuso por el reino en ese año, pero en Madrid se aplicaron en 1665 .

La de "error de medida", de 1667 , procede del fraude con que lns taberneros vendian la arroba de vino a II azumbres, siendo la medida de i I y cuarto ruartillos. $\rightarrow$

I. a de los "nuevos impuestos" data de 1675 .

\section{Diferentes sisas menores y ramos de otras}

El aprovechamiento del arriendo de corrales de comedias se aplica a la sisa de la sexta parte para mayor aumento y satisfacción de ellas.

La sisa de la primera onza de azúcar es ramo también de la sexta parte; fué concedida en ${ }^{6} 617$ cuando la Corte volvió a $\mathrm{Ma}$ drid; se cobra según postura.

La de la segunda onza de azúcar se cobra en la misma forma; fué impuesta en I660 para el pago de 200.000 ducados que Madrid sirvió a Su Majestad para la guerra de Portugal.

I.a de los pescados se cobra una onza en libra de los fres:os y escabechados; pertenece a la del cuarto de Palacio y procede tambièn de la vuelta de la Corte.

La del tocino de 8.000 soldados; se cobra un real por cabeza de cerdo y un maravedí por cada libra, concedida por las Cortes.

I.a del aceite de tres millones; se cobran 33 maravedises por arroba; se concedió en 1657 .

La del aceite de 24 millones; es de cuatro reales por arroba; se concedió en 1667.

La del tabaco del casco de Madrid y todas las villas y !ugares de su partido: se con:edió en 1673 por el servicio a Su Majestad de 700.000 ducados.

El aprovechamiento de cajones de la Plaza Mayor y plazuelas, donde se venda pescado, fruta y verduras. En la Plaza Mayor son 3 I 5 los cajones: precio, dos ducados. Por los de la plazuela de Santo Domingo, red de San Luis y plazuela de Antón M.artin-son 44 los cajones-, también dos ducados. Por las de San Ildefonso y Rastro un ducado. Se aplica a la sisa del cuarto 72 de Palacio. 
La de dos maravedises por libra de nieve y hielo está agregada a la renta del tabaco.

I a de un real por libra de cacao y chocolate, por el servicio que se hizo a Madrid de 500.000 ducados; data de 1676 .

La de tocino de los nuevos impuestos, tres maravedises en libra y nueve por cada cabeza, agregada a la de 24 millones; de 1678 .

La de la cerca, un cuartillo en libra. Por la entrada de la reina doña María Luisa de Borbón: data de r63o.

$\mathrm{La}$ de un cuartillo por arroba de vino; data de 1630 . Procede de los gastos que ocasionó la entrada dé la reina doña Mariana de Nerburg.

La de cuatro maravedises en libra de aceite data de i7r8; Con destino a fábrica de los cuarteles de los Guardias de Corps y su manutención.

En 1686 mandó el rey que las sisas de los nuevos impuestos que había ordenado cesar en todo el reino corriesen en el caso de Maclrid mediate lo que se le ha consultado por el Consejo, para que en su lugar se quitasen los siguientes:

Dos sisas sobre la nieve y el hielo, que cobran dos maravedises en libra en los seis meses de verano y cuatro en los cle invierno y otra de dos maravedises en todo el año, que llamaban la antigua.

La de pescado, un maravedís la libra por el seco, curadillo, salmón cexial y dos en los escabeches y cuatro por el salmón fresco, anguilas y lampones.

I-a de medio real y un cuartillo por libra de ceras.

La de una onza en libra de jabón.

La de una onza en libra de velas de sebo.

I a de cuatro maravedises por azumbre de aloja y un real por arroba de miel.

La de cuatro maravedises por libra de hierro y metales. (Ver detalles página 63 , etc.).

La administración de sisas la tiene Madrid desde 1631 ; antes lo era por una Junta formada en 1613. Dispúsose que el corregidor y caballeros regidores se ocuparan de la cobranza y distribución de las sisas, rentas, pósito y previsión de mantenimientos, dando cuenta de las resoluciones a la sala de gobierno del Concejo. 


\section{Comisión de obrería y guardarropa}

I.a formaban dos caballeros regidores, uno antiguo y otro moderno.

Conose de lo referente a lo que hay en la casa llamada del corralón. en las Vistillas de San Francisco, e interviene en la concesión y uso de lo que en dicha casa se guarda, por lo que es necesario hacer inventarios rigurosos. Antes esa casa-almacén hallábase en Puerta de Moros.

\section{Comisión de veintenas}

Fórmanla dos caballeros capitulares, uno antiguo y otrn moderno. Ocúpase de la enajenación de casas, viñas y en general de las fincas del procomún.

\section{Comisión de Abastos}

Se refiere a los abastos de aceite, jabón, pescado, tocino, velas de sebo. Las de carne, carbón y nieve son comisiones distintas.

Antiguamente el abastecimiento lo hacían los tratantes a su placer, como y cuando querían, con perjuicio del vecindario. Ello obligó a intervenir al Ayuntamiento.

El concurso para el abasto de velas de sebo se hace para San Juan.

El de aceite se regula anualmente, calculándose el consumo en 84.000 arrobas. Su peso es de 25 libras. Vendido al por memenor se redueen a 22 libras menores y tres cuarterones enanos. For cada arroba menor que los mozos cargan en los almacenes. dan 16 maravedises al obligado, y sobre esto se añaden cuatro reales, que debe pagar al día a los que lo venden por las calles; hay otros mozos que se llaman cuarteleros que llevan el aceite a las tiendas, y éstos perciben ocho maravedises, que cobran del tenlero. De cada siete arrobas mayores se hacen ocho menores. Los duros que gravan el aceite son:

Por la sisa de 24 millones ..........

Por la del milloncejo ................

Por la de hospitales .................

Por alsabala y cientos ............ 58

I70 maravedises

Total ............. $\frac{5}{336} \quad$ "


Además paga desde 1717 por cada libra que vende al por menor cuatro maravedises, que se aplican a la fabricación de cuarteles.

Por tocino se pagan to maravedises por cada hoja-medio tacino-que entra en los saladeros y que se distribuye asi:

A los agregados de 24 millones ... 3 maravedises

A los 8.000 soldados ................ I "

A la nueva de carnes ............. 2 "

A la ordinaria de carnes ........... 2 "

A la moderada de carnes ........... 2 "

Agrégase de carga al obligado el io por roo de las cabezas que salen para las carnicerías, y de esto paga 24 reales por cabcza, por razón de alcabala de la venta de despojos, para lo cual se permite unas tablas fuera de puertas de las carnicerías, concedida por el Concejo en r7r2.

Por cada cabeza de canalea paga al obligado ocho reales.

Por cada cabeza que consume en salchichas, adobado o de sazo para sacar hijadas paga 24 reales.

En I 7 I3 se impuso un derecho de cuatro reales por cabeza para fábrica y reedificación del puente de Toledo.

Por jabón se pagan Ioo maravedises por arroba (o sea cuatro por libra) por lo que toca a sisas municipales. Por lo que toca a Su Majestad, lo mismo. Por alcabala, 50 maravedises. Pur los cuatro y medio por ciento antiguos y renovados, 34 . Por repartimiento parra cercas, tres. Al año, 600 reales, por una aldehala que se da a los niños de la Doctrina.

F.l pescado paga por alcabala y cientos la sisa de la onza de pescados frescos y escabechados.

Por acuerdo de 8 de agosto de 1708 se resolvió gravar con I2.000 reales vellón cada año para el sustento de los niños de la Doctrina.

\section{Mariano García Cortes}

